\title{
BMJ Open Prevalence and correlates of alcohol and tobacco use among key populations in Togo in 2017: a cross-sectional study
}

\author{
Alexandra Marie Bitty-Anderson, ${ }^{1}$ Fifonsi Adjidossi Gbeasor-Komlanvi (D) ,2,3 \\ Pascal Johnson, ${ }^{3}$ Essèboè K Sewu, ${ }^{3}$ Claver A Dagnra, ${ }^{4}$ Mounerou Salou, ${ }^{4}$ \\ Tetouyaba J Blatome, ${ }^{3}$ Antoine Jaquet, ${ }^{5,6}$ Patrick Ahuatchi Coffie, , ${ }^{1,6,7}$ \\ Didier Koumavi Ekouevi ${ }^{1,2,3,5}$
}

To cite: Bitty-Anderson AM, Gbeasor-Komlanvi FA, Johnson P, et al. Prevalence and correlates of alcohol and tobacco use among key populations in Togo in 2017: a cross-sectional study. BMJ Open 2019;9:e028934. doi:10.1136/ bmjopen-2019-028934

- Prepublication history for this paper is available online. To view these files please visit the journal online (http://dx.doi org/10.1136/bmjopen-2019028934).

Received 18 January 2019 Revised 06 September 2019 Accepted 23 September 2019

Check for updates

(C) Author(s) (or their employer(s)) 2019. Re-use permitted under CC BY-NC. No commercial re-use. See rights and permissions. Published by BMJ.

For numbered affiliations see end of article.

Correspondence to Dr Didier Koumavi Ekouevi; didier.ekouevi@gmail.com

\section{ABSTRACT}

Objectives The aim of this study was to estimate alcohol and tobacco use prevalence and their correlates among female sex workers (FSW), men who have sex with men (MSM) and drug users (DU) in Togo.

Design, setting and participants A cross-sectional bio-behavioural study was conducted among 2115 MSM, FSW and DU in 2017 using a respondent-driven sampling method, in the eight biggest towns of Togo. Selection criteria for the MSM were being male and having had oral or anal intercourse with a man in the previous 12 months; for FSW, being a female and having exchanged sex for money in the previous 12 months; and for DU, consuming heroin, cocaine or hashish for MSM, FSW and DU, respectively. All participants had to be at least 18 years old and residing in the territory for the past 3 months. Results The prevalence of alcohol consumption, hazardous/harmful consumption and binge drinking was $64.8 \%, 38.4 \%$ and $45.5 \%$, respectively. Current tobacco use was reported by $30.6 \%$ of participants and HIV prevalence was estimated at $12.5 \%$. DU were more likely to engage in binge drinking compared with other key populations (adjusted odds ratio $(\mathrm{aOR})=2.0 ; 95 \% \mathrm{Cl} 1.4$ to 2.8; $p=0.001$ ). Participants who were identified as having hazardous/harmful alcohol consumption had almost three times the odds of tobacco consumption than those with no risky consumption (aOR=2.6; $95 \% \mathrm{Cl} 2.0$ to $3.4 ; \mathrm{p}=0.001$ ) Hazardous/harmful alcohol consumption was three times more likely among participants with severe psychological distress compared with those with no psychological distress (aOR=3.3, 95\% Cl 2.2 to $5.1 ; p=0.001)$. Conclusion Findings from this study demonstrate the need for the integration of mental health and substance abuse reduction interventions into HIV prevention programme, particularly those geared towards key populations.

\section{INTRODUCTION}

Sub-Saharan Africa (SSA) is the region of the world that is most affected by the HIV/AIDS epidemic: with only $12 \%$ of the global population, SSA accounts for an estimated $71 \%$ of the world's burden of HIV infection and $74 \%$ of world's AIDS-related deaths. ${ }^{1}$ In West and Central Africa, the HIV epidemic is described

\section{Strengths and limitations of this study}

- This study is among the first in sub-Saharan Africa exploring the patterns of alcohol and tobacco consumption among the three main groups of key populations.

- This study had a consistent sample size.

- The use of internationally validated instruments to assess alcohol and tobacco consumption, as well as psychological distress, minimised bias.

- The main limitation of our study is that it was based on self-reported data which could be a potential source of recall bias or social desirability bias.

as generalised and driven by heterosexual sex with an estimated prevalence of $2.2 \% .^{1}$ However, in key populations, populations at higher risk of HIV such as female sex workers (FSW), men who have sex with men (MSM) and injection drug users (DU), the reported prevalence rates are disproportionally high compared with those of the general population. ${ }^{23}$ In Togo, HIV prevalence among key populations ranges from $11 \%$ to $13 \%$ compared with $2.1 \%$ in the general population. ${ }^{4}$ Several biological, behavioural and structural risk factors are associated with this high HIV rate among key populations: unprotected sex, presence of other sexually transmitted infections (STIs), lack of access to condoms, multiple concurrent sex partners (males and females for MSM), lack of access to healthcare and prevention services, physical and sexual violence, challenging legal and sociopolitical environment, poverty, sociopolitical stigma and discrimination. ${ }^{23}$

Other risk factors associated with sexual risk behaviours and thus contributing to HIV transmission include alcohol and tobacco consumption. Alcohol, a psychoactive substance with dependence-producing properties, has been an integral part of 
many cultures for several centuries. ${ }^{5}$ The harmful use of alcohol and its consequences make its consumption a public health problem. More than 200 disease and injury conditions including alcohol dependence, liver cirrhosis, cancers and injuries are the consequences of the harmful use of alcohol. ${ }^{5}$ In 2012, it was reported that $5.9 \%$ of all global deaths and $5.1 \%$ of the global burden of disease and injury were the consequences of harmful alcohol consumption. ${ }^{5}$ Recent research studies have also uncovered a causal relationship between the harmful use of alcohol and infectious diseases, including HIV. ${ }^{5-7}$ This relation could be attributed to the fact that alcohol influences cognitive abilities and decision making, and affects condom negotiation and correct condom use. ${ }^{8}$ Among key populations, particularly sex workers, alcohol consumption is seen as a sexual enhancer and work requirement which in many cases leads to an increased likelihood of unprotected sex, economic loss, interference with family responsibilities and sexual violence. ${ }^{7910}$

Tobacco consumption is also one of the biggest public health challenges of the 21st century, with a clear, causal link between tobacco use and health. It is estimated that tobacco use kills half of its users and is responsible for the death of more than 7 million people a year. Approximately $80 \%$ of tobacco users live in low/middle-income countries. ${ }^{11}$ Tobacco use is one the main risk factors for lung cancer, disability and death from non-communicable chronic diseases, and also an increased risk of death from communicable diseases. ${ }^{12}{ }^{13}$ For PLHIV, tobacco use is a risk factor for HIV-related comorbidities and premature death. ${ }^{14}$ Estimates in Togo put the prevalence of alcohol and tobacco consumption at $53.7 \%$ and $8.5 \%$, respectively, in the general population. ${ }^{15}$

Both alcohol and tobacco consumption play an important role in the HIV epidemic in SSA. With key populations being an important catalyst of the HIV epidemic in SSA and particularly in West Africa, it is important that patterns of alcohol and tobacco consumption be explored among these populations. However, there is a dearth of data on the consumption of addictive substances such as tobacco and alcohol among the three main key populations in SSA. Of the few studies on key populations completed in Togo, none has explored alcohol and tobacco consumption and very few studies in West Africa have explored alcohol and tobacco consumption across the three key populations. The aim of this study was to estimate the prevalence of alcohol and tobacco consumption and to assess their correlates among FSW, MSM and DU in Togo.

\section{METHODS}

\section{Study design, sampling and recruitment}

This study was a bio-behavioural cross-sectional study conducted from August to September 2017 in Togo. Togo is a country of West Africa, with a population of 7.6 million inhabitants in 2018, covering 57000 square kilometres with an average density of 133 inhabitants per square kilometres, an infant mortality of 45.2/1000 and an estimated life expectancy of 64.5 years old. The HIV prevalence in Togo is estimated at $2.1 \%$, with a high prevalence among key population groups. ${ }^{4}$ Togo is divided into five regions and in each region, based on the mapping and size estimation studies previously carried out in Togo, ${ }^{16}$ towns with the highest number of key populations were selected: Dapaong in the Savanes region; Kara in Kara region; Sokodé in the Centrale region; Atakpamé and Kpalimé in the Plateaux region and Tsévié, Aného and Lomé, the capital city in the Maritime region. Prior to the study, locations (associations and hot spots) specific to each group of key population were identified during preliminary visits with the help of leaders from these communities. DU and FSW were recruited in drugdealing/consumption locations and brothels (licensed or not), respectively. MSM were recruited using a respondentdriven sampling (RDS) method. ${ }^{17} 18$ MSM community leaders were the first 'seeds'. A total of 28 seeds were identified at first based on their roles in their community and on their representativeness. Each seed from the first wave selected had to represent at least one MSM subgroup, based on how MSM self-identify as bisexuals or gays. ${ }^{19} 20$ Each participant was then given three coupons with a unique identification code to recruit three other seeds in their network until the required sample size for each group was reached. Inclusion criteria for the three groups were being 18 years or older, living/working/studying in Togo for a minimum of 3 months at the time of the study, and being in possession of a recruitment coupon. In addition to these criteria, criteria specific to MSM were having had anal and/or oral sex with a man in the previous 12 months, for FSW having had sex in exchange for money as a compensation in the previous 12 months and for DU, consuming heroin, cocaine or hashish at the time of the study.

\section{Sample size estimation}

The sample size estimation was based on the estimated prevalence of hazardous alcohol drinking among key populations of $9.1 \% .^{21}$ We also took into account the prevalence of tobacco use, with the assumption that tobacco use prevalence in the key populations would be twice that of the general population. Hence, with a tobacco use prevalence of $6.8 \%$ in the general population, the expected prevalence of tobacco use among key populations was $13.6 \% .{ }^{15}$ With a precision of $3 \%$ and an assumption of $10 \%$ of missing data, the minimum sample size was estimated at 552 participants per group at a minimum. Thus, to allow a comparison between groups, the total sample size estimated for the three groups of key populations was 1656 .

\section{Study procedures}

After eligibility screening and written informed consent approval, trained study staff (medical students) administered a structured and standardised questionnaire during a face-to-face interview. The interviews took place 
in the MSM community-based organisations (CBOs) for the MSM, for the FSW, in selected bars around the main 'hot spots' from which they were recruited and for the DU, recruitment occurred in the smoking spots in the 'ghettos'. The questionnaire was constructed based on validated tools such as the Alcohol Use Disorders Identification Test (AUDIT) ${ }^{22}$ and a subset of the Tobacco Questions for Surveys ${ }^{23}$ to assess alcohol and tobacco consumption, respectively. The Kessler Psychological Distress Scale (K10) ${ }^{24}$ was used to measure psychological distress and the Family Health International 360 validated guide for bio-behavioural surveys ${ }^{25}$ was adapted to collect information on socio-demographic characteristics, risky sexual behaviours, STIs, HIV prevention methods, HIV testing history, access to healthcare services and HIV knowledge. The questionnaires were used across the three populations with slight adaptations depending on the population.

\section{Scores and operational definitions}

The AUDIT was used to assess alcohol consumption. The AUDIT is a set of 10-item standardised screening instrument measuring self-reported alcohol use in the past 12 months, alcohol dependence symptoms and alcoholrelated problems to screen for excessive drinking. Each question of the AUDIT can obtain a score from 0 to $4 .{ }^{4} \mathrm{~A}$ score $\geq 8$ for men and $\geq 7$ for women indicates hazardous/ harmful drinking, while a score of 0 indicates a nondrinker; moderate alcohol use lies in-between. ${ }^{22} 2627$ Binge drinking or heavy episodic drinking was defined as the consumption of six or more alcohol drinks on at least one occasion in the past 30 days (third item of the AUDIT). ${ }^{22}$

Tobacco use was assessed using six questions indicating participants' smoking habits, frequency of smoking, history of smoking, type of products smoked and attempts at stopping to smoke. ${ }^{23}$

The K10 was used to measure psychological distress. This scale has been examined and validated among several populations and aims at measuring anxiety and depression with a 10-item questionnaire, each question pertaining to an emotional state and a five-level response scale for each response. The score obtained from the scale allows us to categorise participants into four categories of psychological distress: severe (score $\geq 30$ ), moderate (score: 25-29), mild (score: 20-24) and none (score $<20) .{ }^{28}$

\section{Laboratory testing}

Written informed consent was obtained prior to blood sample collection. Among the 2115 key populations recruited for the study, $91.8 \%$ gave their written informed consent for blood sample collection. Blood samples were collected to test for HIV and Syphilis using SD Biolane Duo (Abbott). Each HIV positive test was confirmed with another HIV rapid test, the First Response HIV 1-2-O Card Test (Premier Medical Corporation Pvt. Ltd). In case of discordant results, samples were tested with the
INNO-LIA HIV I/II Score (20T) (Fujirebio) line immunoassay. All biological tests analyses were completed in the main HIV laboratory research unit, the Molecular Biology Laboratory (BIOLIM) at the University of Lomé.

\section{Statistical analysis}

Descriptive statistics were performed and results were presented with frequency tabulations and percentages. Prevalences were estimated with their 95\% CI. Univariate and multivariate logistic regression were performed to identify factors associated with: (i) hazardous/harmful alcohol consumption, (ii) binge drinking and (iii) current tobacco consumption. For model building, characteristics that had a $p$ value $<0.20$ in univariate analysis were considered for the full multivariable models, which were then finalised using a stepwise, backward elimination approach. The three models did not include the variable 'sex' as the four groups were already categorised according to sex. All analyses were performed using $\mathrm{R}$ software.

\section{Ethical consideration}

This study was approved by the 'Comité de Bioéthique pour la Recherche en Santé (CBRS)' (Bioethics Committee for Health Research) from the Togo Ministry of Health. Participants provided written consent prior to participation. Potential participants were told about the study purpose and procedures, potential risks and protections, and compensation. Informed consent was documented with signed consent forms.

\section{Patient and public involvement}

Members of key populations were involved during the study design and data collection phases of the study. They were consulted prior to the study for their input on the best method to reach out to key populations and they were actively involved in the recruitment process.

\section{RESULTS \\ Socio-demographic characteristics}

A total of $641 \mathrm{MSM}, 537 \mathrm{DU}$ and $937 \mathrm{FSW}$, with a median age of 25 years, IQR [21-32 years] participated in the study. The majority of the sample $(n=1443 ; 54.0 \%)$ had a secondary school education level and $76.7 \%$ were Christians $(n=1621)$. Approximately two-thirds of the sample $(\mathrm{n}=1278 ; 60.4 \%)$ were likely to not have any psychological distress and $6.4 \%(\mathrm{n}=136)$ were identified as having severe psychological distress, the highest among DU $(\mathrm{n}=68 ; 12.7 \%)$. The HIV prevalence was $12.5 \%$ across the three populations, with the highest prevalence among MSM (20.4\%). Study participants were informed of their blood test results by trained health professionals from HIV clinics. Newly diagnosed HIV positive patients were referred to an HIV clinic for HIV treatment and care. Socio-demographic and health characteristics are summarised in table 1. 
Table 1 Socio-demographic and health characteristics

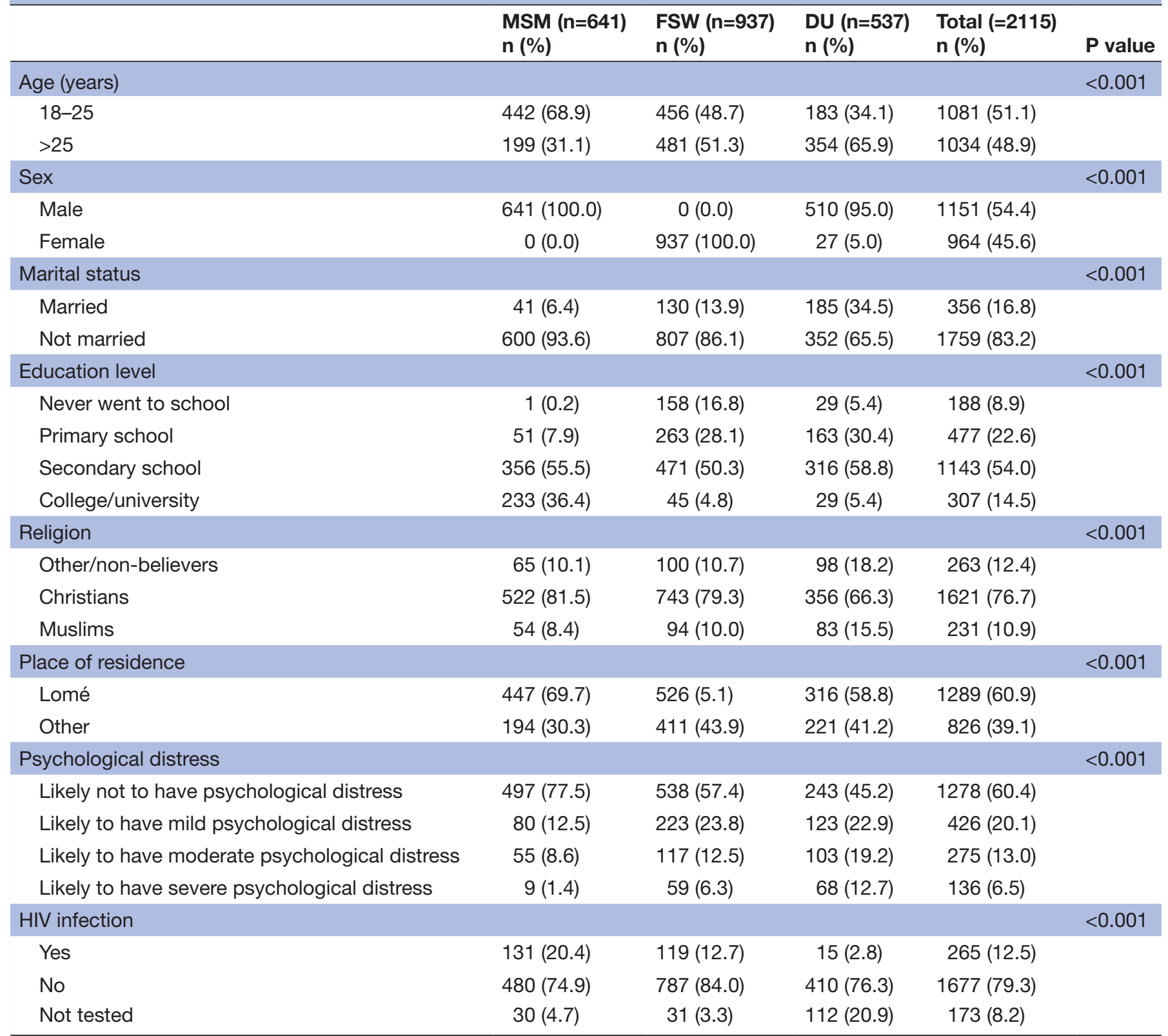

DU, drug users; FSW, female sex workers; MSM, men who have sex with men.

\section{Alcohol and tobacco consumption}

Alcohol and tobacco consumption patterns are presented in table 2. Overall, the prevalence of alcohol consumption among the three groups was $64.8 \%$. Most participants were identified as having a hazardous/harmful alcohol consumption $(\mathrm{n}=813 ; 38.4 \%)$, with the highest proportion among DU (62.4\% among DU; $36.7 \%$ among FSW; and $20.9 \%$ among MSM; $\mathrm{p}<0.001)$. More than a quarter of FSW ( $\mathrm{n}=275 ; 29.4 \%)$ were moderate drinkers. The MSM subgroup had the highest proportion of non-drinkers $(\mathrm{n}=338 ; 52.7 \%)$, followed by FSW $(\mathrm{n}=318 ; 33.9 \%)$. The overall prevalence of binge drinking was $45.5 \%$ and was the highest among DU (67.0\%) (table 2).

The prevalence of tobacco consumption was $30.6 \%$ among the three groups. DU had the highest proportion of smokers $(80.8 \%)$. The highest proportion of nonsmokers were FSW $(\mathrm{n}=821 ; 87.6 \%)$, followed by MSM $(\mathrm{n}=544,84.9 \%)$. Of the people who smoked, $63.1 \%$ were smoking every day, including $79.0 \%$ of DU, $42.2 \%$ of FSW and $16.5 \%$ of MSM.

\section{Factors associated with alcohol consumption}

Table 3 reports the results of the multivariable logistic regression model that describes the association between the independent variables and the hazardous/harmful consumption of alcohol and binge drinking. The odds of hazardous/harmful alcohol consumption were significantly higher among non-believers or other adjusted odds ratio $(\mathrm{aOR}=0.7 ; 95 \%$ CI 0.5 to $0.9 ; \mathrm{p}=0.001)$ than among Muslims $(\mathrm{aOR}=0.4 ; 95 \% \mathrm{CI} 0.3$ to $0.6 ; \mathrm{p}=0.001)$ and Christians 
Table 2 Alcohol and tobacco consumption patterns among key populations in Togo in 2017

\begin{tabular}{|c|c|c|c|c|c|}
\hline Addictive behaviour & $\begin{array}{l}\text { MSM (n=641) } \\
n(\%)\end{array}$ & $\begin{array}{l}\text { FSW (n=937) } \\
n(\%)\end{array}$ & $\begin{array}{l}\text { DU (n=537) } \\
n(\%)\end{array}$ & $\begin{array}{l}\text { Total }(n=2115) \\
N(\%)\end{array}$ & $P$ value \\
\hline Alcohol consumption & & & & & $<0.001$ \\
\hline Moderate drinking ${ }^{\star}$ & $169(26.4)$ & $275(29.4)$ & $114(21.2)$ & $558(26.4)$ & \\
\hline Hazardous consumption & $134(20.9)$ & $344(36.7)$ & $335(62.4)$ & $813(38.4)$ & \\
\hline Tobacco use & & & & & $<0.001$ \\
\hline Yes & $97(15.1)$ & $116(12.4)$ & $434(80.8)$ & $647(30.6)$ & \\
\hline Every day & $16(16.5)$ & $49(42.2)$ & $343(79.0)$ & $408(63.1)$ & \\
\hline No & $544(84.9)$ & $821(87.6)$ & 103 (19.2) & $1468(69.4)$ & \\
\hline
\end{tabular}

*Moderate drinking levels depend on sex (differences in metabolism for females and males): AUDIT score: 1-6 for females and AUDIT score: $1-7$ for males.

†Binge drinking is defined as the consumption of six or more alcohol drinks at least once per month in one occasion (Question 3 of the AUDIT).

DU, drug users; FSW, female sex workers; MSM, men who have sex with men.

$(\mathrm{aOR}=0.7 ; 95 \% \mathrm{CI}=0.5$ to $0.9 ; \mathrm{p}=0.001) . \mathrm{FSW} \quad(\mathrm{aOR}=1.6$; $95 \%$ CI 1.3 to $2.1 ; \mathrm{p}=0.001)$ and DU $(\mathrm{aOR}=2.0 ; 95 \% \mathrm{CI}$ 1.4 to $2.8 ; \mathrm{p}=0.001$ ) were more likely to engage in binge drinking compared with MSM. The place of residence, whether in the capital city of Lomé or in other towns, was also associated with hazardous/harmful alcohol consumption and binge drinking so that people living in other towns were almost three times more likely to have hazardous/ harmful alcohol consumption $(\mathrm{aOR}=2.8 ; 95 \%$ CI 2.2 to 3.4; $\mathrm{p}=0.001)$ or engage in binge drinking $(\mathrm{aOR}=2.5 ; 95 \%$ CI 2.0 to $3.0 ; p=0.001$ ) than those living in the capital city of Lomé. Psychological distress was also a risk factor for hazardous/harmful alcohol consumption and binge drinking. Participants with severe psychological distress were three times $(\mathrm{aOR}=3.3,95 \%$ CI 2.2 to $5.1 ; \mathrm{p}=0.001)$ and twice $(\mathrm{aOR}=2.2,95 \%$ CI 1.5 to $3.4 ; \mathrm{p}=0.001)$ more likely to be engaged in hazardous/harmful alcohol consumption and binge drinking, respectively, than those with no psychological distress. The odds of hazardous/harmful alcohol consumption and binge drinking increased as the severity of psychological distress increased. In addition, being a DU was significantly associated with hazardous/harmful alcohol consumption and binge drinking. Compared with MSM and FSW, DU had two times the odds of hazardous/ harmful alcohol consumption $(\mathrm{aOR}=2.4 ; 95 \%$ CI 1.7 to 3.4; $\mathrm{p}=0.001$ ) and two times the odds of binge drinking compared with MSM and FSW (aOR=2.0; 95\% CI 1.4 to 2.8). Finally, being 25 years old and older $(\mathrm{aOR}=1.3 ; 95 \% \mathrm{CI}$ 1.1 to 1.6$)$, tobacco use $(\mathrm{aOR}=2.6 ; 95 \%$ CI 2.0 to 3.4$)$, being HIV positive ( $\mathrm{aOR}=0.7 ; 95 \% \mathrm{CI} 0.5$ to 0.9 ) were significantly associated with both hazardous/harmful alcohol consumption and binge drinking.

\section{Factors associated with tobacco use}

In multivariable analysis, living in cities other than Lomé (the capital city) $(\mathrm{aOR}=0.6 ; 95 \%$ CI 0.5 to 0.8$)$, hazardous/harmful alcohol consumption (aOR=2.6; 95\% CI 2.0 to 3.4 ), having mild ( $\mathrm{aOR}=1.5 ; 95 \%$ CI 1.1 to 2.1) or moderate $(\mathrm{aOR}=2.0 ; 95 \%$ CI 1.3 to 2.8$)$ psychological distress, being a FSW ( $\mathrm{aOR}=0.6 ; 95 \%$ CI 0.4 to 0.9$)$ and being a DU (aOR=17.9; 95\% CI 12.4 to 26.4) were factors associated with tobacco use (table 4 ).

\section{DISCUSSION}

The aim of this study was to assess the prevalence of hazardous/harmful, binge alcohol consumption as well as tobacco consumption, and explore correlates of heavy alcohol consumption and tobacco use in three key populations in Togo. We observed a high prevalence of hazardous/harmful alcohol consumption and binge drinking. Alcohol consumption was frequent among FSW and much more among DU. In addition, there was a dose-response effect relationship between alcohol consumption and psychological distress across all three populations. Tobacco use was highly prevalent among DU and among people who had a hazardous/harmful alcohol consumption.

Alcohol consumption is highly prevalent among key populations groups: more than half of the sample were categorised as moderate or hazardous drinkers. This has been corroborated in the literature among key population groups. In a recent study in Kenya, among 1476 MSM, $44 \%$ of the sample had a hazardous alcohol consumption, and no relationship was found between alcohol and tobacco consumption and HIV infection. ${ }^{29}$ In another study among $3588 \mathrm{MSM}$ in China, alcohol prevalence was $56.1 \%$ with $16.8 \%$ of them being binge drinkers and $14.4 \%$ being recent hazardous drinkers, using the WHO AUDIT-C scale. ${ }^{30}$ Recent alcohol misuse was associated with increased sexual and HIV/syphilis risks as well as 


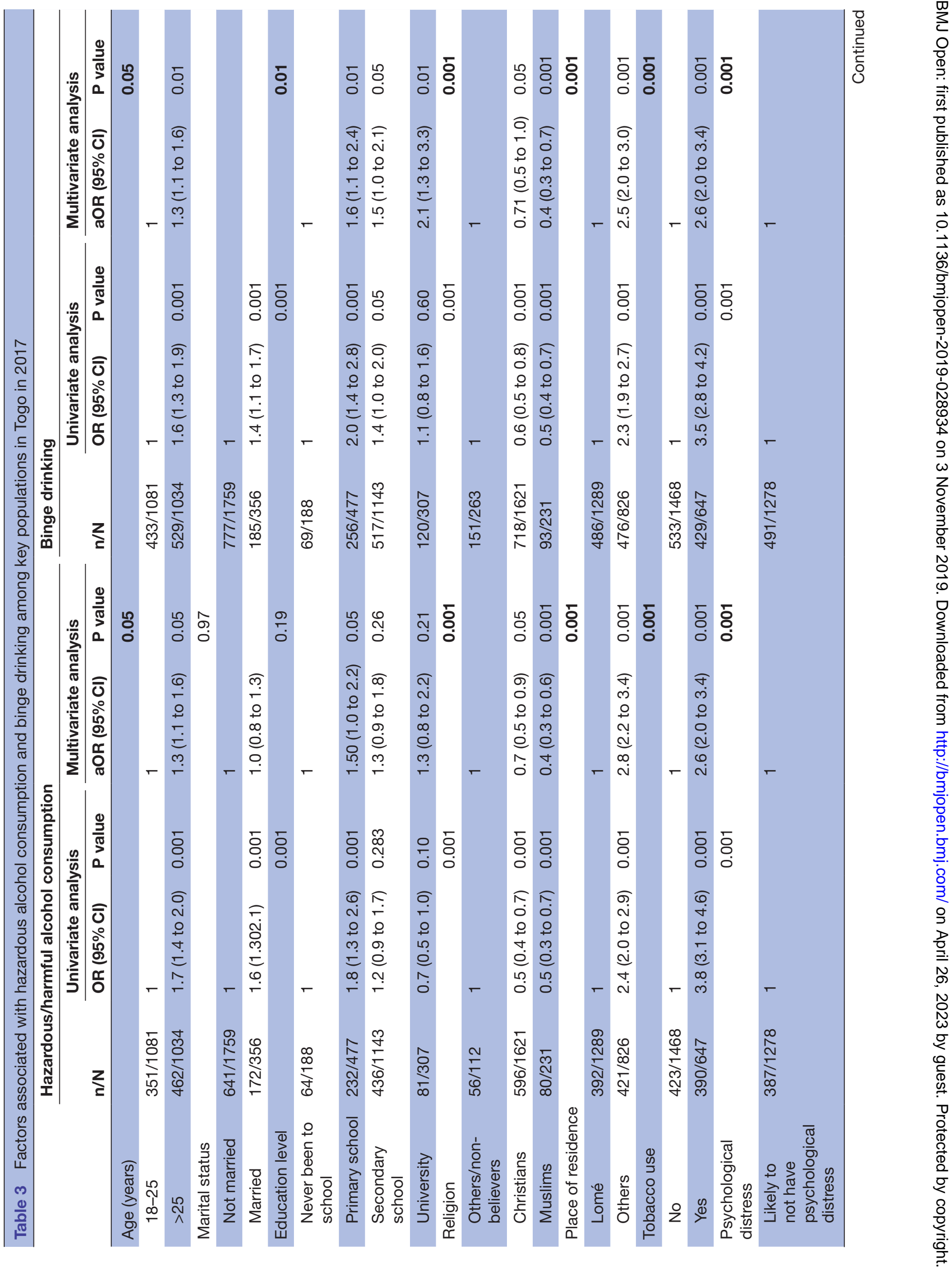




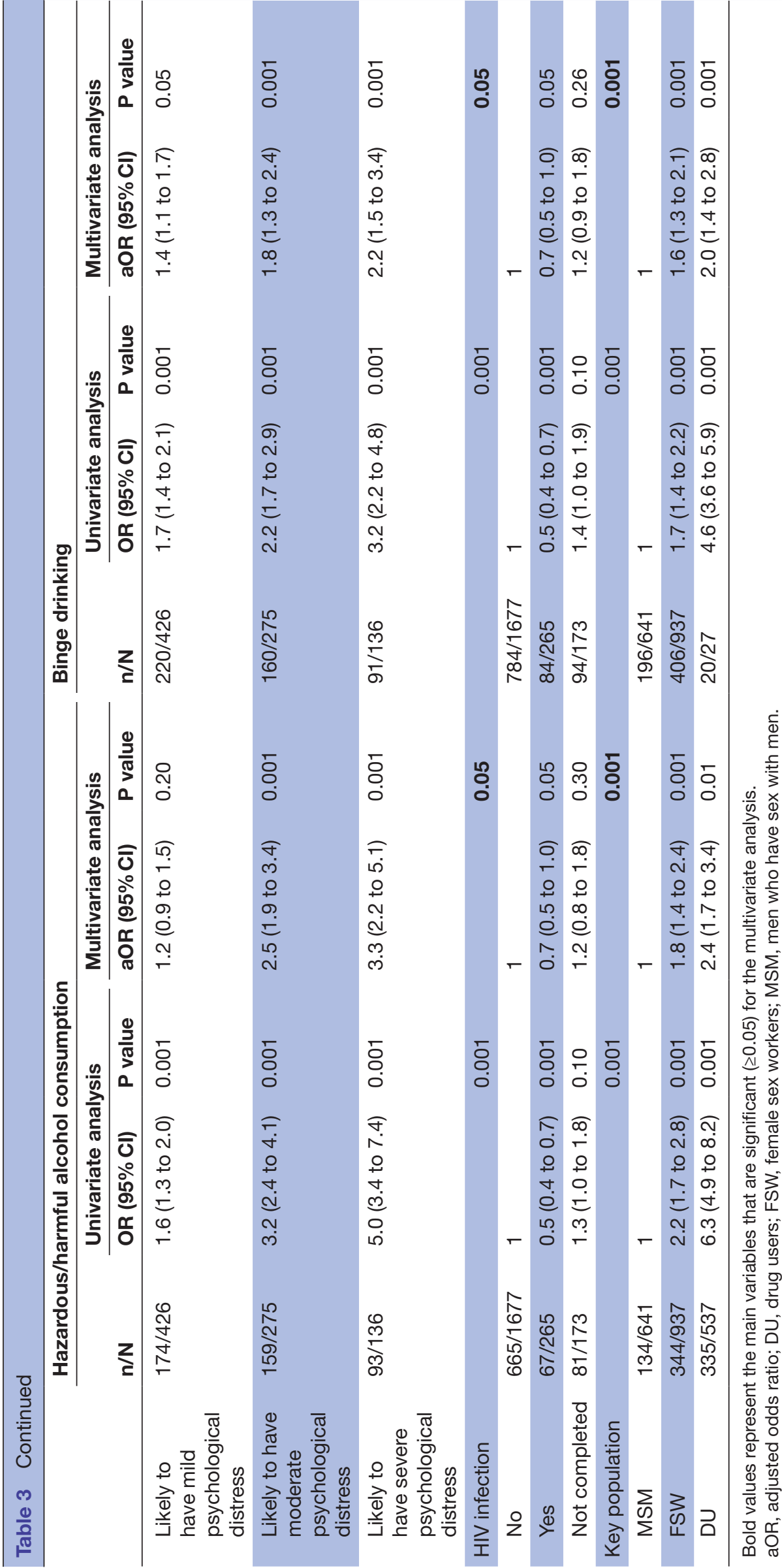


Table 4 Factors associated with tobacco use among key populations in Togo in 2017

\begin{tabular}{|c|c|c|c|c|c|}
\hline & & Univariate analysi & & Multivariate analy & \\
\hline & $n / N$ & OR $(95 \% \mathrm{Cl})$ & $P$ value & aOR $(95 \% \mathrm{Cl})$ & $P$ value \\
\hline Age (years) & & & & & 0.14 \\
\hline $18-25$ & $280 / 1081$ & 1 & & 1 & \\
\hline$>25$ & $367 / 1034$ & 1.6 (1.3 to 1.9$)$ & 0.001 & 0.81 (0.6 to 1.1$)$ & 0.15 \\
\hline Marital status & & & & & 0.22 \\
\hline Not married & $481 / 1759$ & 1 & & 1 & \\
\hline Married & 356 & 2.3 (1.8 to 2.9$)$ & 0.001 & 0.8 (0.6 to 1.1$)$ & 0.22 \\
\hline Level of education & & & 0.001 & & 0.32 \\
\hline None & $42 / 188$ & 1 & & 1 & \\
\hline Primary school & $186 / 477$ & 2.2 (1.5 to 3.3 ) & 0.001 & 1.3 (0.8 to 2.3 ) & 0.26 \\
\hline Secondary/high school & $364 / 1143$ & 1.6 (1.1 to 2.4$)$ & 0.01 & $1.2(0.7$ to 1.9$)$ & 0.59 \\
\hline University & $55 / 307$ & 0.8 (0.5 to 1.2$)$ & 0.230 & 0.9 (0.5 to 1.7$)$ & 0.73 \\
\hline Religion & & & 0.001 & & 0.05 \\
\hline Others/non-believers & $40 / 112$ & 1 & & 1 & \\
\hline Christians & $436 / 1621$ & 0.5 (0.4 to 0.6$)$ & 0.001 & 0.7 (0.5 to 1.0$)$ & 0.10 \\
\hline Muslims & $96 / 231$ & 0.9 (0.6 to 1.3$)$ & 0.63 & 1.1 (0.7 to 1.9$)$ & 0.60 \\
\hline Place of residence & & & & & 0.001 \\
\hline Lomé & $400 / 1289$ & 1 & & 1 & \\
\hline Others & $247 / 826$ & 1.0 (0.8 to 1.2$)$ & 0.59 & 0.6 (0.5 to 0.8$)$ & 0.001 \\
\hline Alcohol consumption & & & & & 0.001 \\
\hline No risky consumption & 257/1302 & 1 & & 1 & \\
\hline Hazardous/harmful drinking & $390 / 813$ & 3.8 (3.1 to 4.6$)$ & 0.001 & 2.6 (2.0 to 3.4 ) & 0.001 \\
\hline Psychological distress & & & 0.001 & & 0.01 \\
\hline Likely to not have psychological distress & $300 / 1278$ & 1 & & 1 & \\
\hline Likely to have mild psychological distress & $150 / 426$ & 1.8 (1.4 to 2.2$)$ & 0.001 & 1.5 (1.1 to 2.1$)$ & 0.01 \\
\hline Likely to have moderate psychological distress & $128 / 275$ & 2.8 (2.2 to 3.7$)$ & 0.001 & 2.0 (1.3 to 2.8$)$ & 0.001 \\
\hline Likely to have severe psychological distress & $69 / 136$ & 3.4 (2.3 to 4.8$)$ & 0.001 & 1.3 (0.8 to 2.2$)$ & 0.30 \\
\hline HIV infection & & & 0.001 & & 0.34 \\
\hline No & $509 / 1677$ & 1 & & 1 & \\
\hline Yes & $44 / 265$ & $0.5(0.3$ to 0.6$)$ & 0.001 & 0.9 (0.6 to 1.3$)$ & 0.51 \\
\hline Not completed & $94 / 173$ & 2.7 (2.0 to 3.8$)$ & 0.001 & 0.7 (0.5 to 1.2$)$ & 0.17 \\
\hline Key populations & & & 0.001 & & 0.001 \\
\hline MSM & $97 / 641$ & 1 & & 1 & \\
\hline FSW & $116 / 937$ & 0.8 (0.6 to 1.1$)$ & 0.12 & $0.6(0.4$ to 0.9$)$ & 0.01 \\
\hline DU & $434 / 537$ & 23.6 (17.5 to 32.2 ) & 0.001 & 17.9 (12.4 to 26.4$)$ & 0.001 \\
\hline
\end{tabular}

Bold values represent the main variables that are significant $(\geq 0.05)$ for the multivariate analysis.

aOR, adjusted odds ratio; DU, drug users; FSW, female sex workers; MSM, men who have sex with men.

sexual risk behaviours including alcohol use before sex, sex without condoms and multiple concurrent partnerships. A prospective cohort study among 1,027 FSW in Uganda found that $78 \%$ of the sample reported using alcohol with $71 \%$ admitting to using alcohol at least once a week, with a reduced prevalence of $54 \%$ after 2 years of intervention. ${ }^{31}$ This emphasises the need for alcohol risk reduction programme and programme specifically focused on the adoption of safer drinking practices integrated into HIV prevention packages and geared towards highly exposed groups. ${ }^{30} 31$

Alcohol and tobacco consumption are particularly relevant to people living with HIV (PLHIV). Studies have demonstrated a negative impact of alcohol, tobacco and drug use on life expectancy for HIV-positive patients. ${ }^{32}$ Alcohol and tobacco use have also been associated with poor adherence to antiretroviral therapy (ART) and the interaction between all those substances leading to a higher 
susceptibility to co-morbidities, opportunistic infections such as tuberculosis. ${ }^{33}{ }^{34}$ In this study, hazardous/harmful alcohol consumption and binge drinking were both significantly associated with tobacco use. ${ }^{33}$ This indicates the need for targeted prevention actions such as smoking cessation treatment and alcohol reducing counselling, among key populations, particularly among key populations living with HIV. A systematic review of interventions to reduce alcohol use among MSM indicated that although interventions such as motivational interviewing appear to be effective among MSM, they are scarce. ${ }^{35}$

Psychological distress was found to have a doseresponse relationship with alcohol consumption. Severe psychological distress was at least twice higher among people with a hazardous/harmful alcohol consumption and people who were binge drinking. This is consistent with other studies that found a relationship between alcohol and drug abuse and psychological symptoms such as depression, anxiety and suicidal ideation among key populations. ${ }^{29} 3637$ Consistent with our findings, a study conducted in Cambodia among MSM found that 38.8\% had severe psychological distress and that severe psychological distress was associated with alcohol and drug use, poor self-reported quality of life and reduced condom use at last sex. ${ }^{36}$ In southern India, a study among FSW found a significant relationship between major depression and alcohol use. ${ }^{38}$ Another study among PLHIV in Uganda found that psychological distress was significantly associated with non-adherence to ART. ${ }^{39}$ This has implication for HIV prevention and further demonstrates the need for integrated services of mental health interventions, psychological support as well as substance abuse reduction programme into HIV prevention programme. In fact, in Togo, the current policy on HIV prevention and care ensures access to HIV prevention and treatment services with the integration of sexual and reproductive services and HIV care services for all citizens including key populations, but mental health interventions are not yet a component of the basic health services package. This would also imply that healthcare workers be sufficiently armed through sufficient and adequate training to screen and refer key populations in need of those interventions.

Very few studies have explored alcohol and tobacco consumption patterns among the three main key populations. This study found quite different patterns of consumption among the three groups, with MSM in this sample being the lowest at-risk group for hazardous/harmful alcohol consumption, binge drinking and tobacco use. DU, on the other hand, appear to be most vulnerable to hazardous/harmful alcohol consumption, binge drinking and tobacco use, as well as the group with the highest prevalence of severe psychological distress. This could potentially indicate that there is a difference in coping strategies for key populations and that behavioural interventions specifically geared towards MSM have elements that perhaps have successfully enhanced their capacity to cope with the stress among the most marginalised groups. For example, studies have demonstrated the effectiveness of CBOs, peer-led interventions and community engagement in HIV prevention among MSM. ${ }^{40-42}$ It is important that targeted interventions be geared towards generating an interest for community building among DU.

Strengths of this study include the large sample size of the three main types of key populations. In addition, to our knowledge, this is the first study in Togo comparing alcohol and tobacco consumption in these key populations using standardised tools (AUDIT, Tobacco Questions for Surveys, and K10). Finally, this study was completed in the eight main cities of Togo and used geographical mapping as well as RDS sampling, which could indicate that the findings of this study reflect the national prevalence of alcohol and tobacco consumption among key populations.

However, there were few limitations including the fact that some variables, such as childhood abuse, stigma or recent trauma which could influence alcohol and tobacco consumption, have not been collected. Interactions between the different groups of key populations (ie, DUs engaging in sex work, MSM who engage in sex work, sex workers who are also MSM) were also not collected. Furthermore, self-reported data used in this study are prone to social desirability and recall bias. Despite these limitations, the results presented in this study make a unique contribution to the literature on alcohol and tobacco use among key populations in West Africa, especially since Togo shares similar characteristics with other countries of West Africa regarding the HIV epidemic (concentrated HIV epidemics with elevated HIV prevalences among key populations), access to treatment and prevention for key populations. ${ }^{343}$ The results could be generalised to other countries in West Africa.

Further research could further explore the relationship between alcohol, tobacco, depression and sexual risk behaviours and HIV infection among key populations. Qualitative studies could also explore the reasons for high alcohol and tobacco consumption among key populations.

\section{CONCLUSION}

Alcohol and tobacco use and abuse are highly prevalent among key populations. Psychological distress and being a DU were both significantly associated with alcohol and tobacco consumption. There is a need for mental health and substance abuse screening, referral and treatment to be addressed and fully integrated into HIV prevention services for key populations. Further research is also needed to explore, through qualitative and quantitative designs, the consequences and impact of alcohol and tobacco consumption, as well as mental health issues such as psychological distress on individuals and its contribution to the HIV epidemic.

\section{Author affiliations}

'PACCI Research Center-Site ANRS Côte d'Ivoire, Abidjan, Côte d'Ivoire

${ }^{2}$ Department of Public Health, Faculty of Health Sciences, University of Lomé, Lomé, Togo 
${ }^{3}$ Centre Africain de Recherches en Epidemiologie et en Santé Publique (CARESP), Lomé, Togo

${ }^{4}$ Faculty of Health Sciences, Molecular Biology Laboratory, University of Lomé, Lomé, Togo

${ }^{5}$ Department of Public Health, INSERM U1219, Bordeaux Population Health Research, University of Bordeaux, Bordeaux, France

${ }^{6}$ Department of Public Health, Institut de Santé Publique Epidémiologie et Développement, University of Bordeaux, Bordeaux, France

${ }^{7}$ Dermatologie et Infectiologie, Unite de Formation et de Recherche des Sciences Medicales, Universite Felix Houphouet-Boigny, Abidjan, Côte d'Ivoire

Contributors AMB-A and FAG-K contributed equally to this paper. AMB-A, FAG-K, PAC and DKE conceived and designed the study with inputs from AJ. PJ, EKS, CAD, MS and TJB facilitated data collection and contributed to analysis of the data. AMB-A and FAG-K analyzed, interpreted the data and drafted the manuscript. PAC, $\mathrm{AJ}$ and DKE revised the manuscript for important intellectual content. All authors participated in the revision process and have approved the final version of the manuscript.

Funding This work was supported by the Centre Africain de Recherche en Epidemiologie et en Santé Publique (African Center for Epidemiology and Public Health Research) and the Togo National HIV/AIDS and Sexually Transmitted Infection Control Program.

\section{Competing interests None declared.}

Patient consent for publication Not required.

Ethics approval This study was reviewed and approved by the Bioethics Committee for Research in Health in Togo (CBRS No. 18/2017/CBRS, 22 June 2017). Consent was obtained from each participant prior to administering the survey questions.

Provenance and peer review Not commissioned; externally peer reviewed.

Data availability statement Data are available upon reasonable request. Data may be obtained from a third party and are not publicly available.

Open access This is an open access article distributed in accordance with the Creative Commons Attribution Non Commercial (CC BY-NC 4.0) license, which permits others to distribute, remix, adapt, build upon this work non-commercially, and license their derivative works on different terms, provided the original work is properly cited, appropriate credit is given, any changes made indicated, and the use is non-commercial. See: http://creativecommons.org/licenses/by-nc/4.0/.

\section{ORCID iD}

Fifonsi Adjidossi Gbeasor-Komlanvi http://orcid.org/0000-0002-1744-0454

\section{REFERENCES}

1 Kharsany ABM, Karim QA. Hiv infection and AIDS in sub-Saharan Africa: current status, challenges and opportunities. Open AIDS J 2016;10:34-48.

2 Djomand G, Quaye S, Sullivan PS. Hiv epidemic among key populations in West Africa. Curr Opin HIV AIDS 2014;9:506-13.

3 HIV and AIDS in West and Central Africa Overview [Internet]. AVERT, 2017. Available: https://www.avert.org/hiv-and-aids-west-andcentral-africa-overview [Accessed 19 Jul 2018].

4 Joint United Nations Programme on HIV/AIDS (UNAIDS). Togo [Internet]. Available: http://www.unaids.org/en/regionscountries/ countries/togo [Accessed 19 Jul 2018].

5 World Health Organization (WHO). Global status report on alcohol and health, 2018 [Internet], 2018. Available: http://www.who.int/ substance_abuse/publications/global_alcohol_report/gsr_2018/en/ [Accessed 10 Oct 2018].

6 Lama TP, Kumoji E. 'Kuor, Ketlogetswe D, et al. Alcohol consumption and risky sexual behavior among persons attending alcohol consumption venues in Gaborone, Botswana. Prevention Science 2016;17:227-36.

7 Sileo KM, Kintu M, Chanes-Mora P, et al. "Such Behaviors Are Not in My Home Village, I Got Them Here": A Qualitative Study of the Influence of Contextual Factors on Alcohol and HIV Risk Behaviors in a Fishing Community on Lake Victoria, Uganda. AIDS Behav 2016;20:537-47.

8 Chersich MF, Rees HV. Causal links between binge drinking patterns, unsafe sex and HIV in South Africa: its time to intervene. Int J STD AIDS 2010;21:2-7.
9 Chen Y, Li X, Shen Z, et al. Drinking reasons and alcohol problems by work venue among female sex workers in Guangxi, China. Subst Use Misuse 2015;50:642-52.

10 Heravian A, Solomon R, Krishnan G, et al. Alcohol consumption patterns and sexual risk behavior among female sex workers in two South Indian communities. Int J Drug Policy 2012;23:498-504.

11 Tobacco [Internet]. World Health organization. Available: http://www. who.int/news-room/fact-sheets/detail/tobacco [Accessed 3 Aug 2018].

12 Commar A, Prasad VK, Tursan d'Espaignet E, et al. Weltgesundheitsorganisation. who global report on trends in prevalence of tobacco smoking 2018:2000-25.

13 World Health Organization. Who global report on trends in prevalence of tobacco smoking, 2015, 2015. Available: http://apps.who.int/iris/ bitstream/10665/156262/1/9789241564922 eng.pdf [Accessed 2 Aug 2018].

14 Reynolds NR. Cigarette smoking and HIV: more evidence for action. AIDS Education and Prevention 2009;21:106-21.

15 Agoudavi K, Santé Mdela. Togo. Rapport Final de l'enquête STEPS Togo 2010 [Internet]. Ministère de la Santé Togo, 2012. Available: http://www.who.int/ncds/surveillance/steps/2010STEPS_Report Togo FR.pdf

16 Conseil National de Lutte contre le sida et les infections sexuellement transmissibles, Republique du Togo. Estimation de la taille et cartographie des sites des hommes ayant des rapports sexuels avec d'autres hommes et des Professionnelles de sexe [Internet]. Republique du Togo, 2015. Available: http://cnlstogo.org/download/ cartographies/Rapport-Estimation-de-la-taille-et-cartographie-HSHet-PS-Togo_30_06_15-OK.pdf

17 Malekinejad M, Johnston LG, Kendall C, et al. Using respondentdriven sampling methodology for HIV biological and behavioral surveillance in international settings: a systematic review. AIDS Behav 2008;12:105-30.

18 Heckathorn DD. Respondent-Driven sampling: a new approach to the study of hidden populations. Soc Probl 1997:44:174-99.10.2307/3096941

19 Cáceres CF, Aggleton P, Galea JT, et al. Social inclusion and HIV/ AIDS. AIDS Lond Engl 2008;22:S45-55.

20 Ross MW, Kajubi P, Mandel JS, et al. Internalized homonegativity/ homophobia is associated with HIV-risk behaviours among Ugandan gay and bisexual men. Int J STD AIDS 2013;24:409-13.

21 Jaquet A, Nouaman M, Tine J, et al. Hepatitis B treatment eligibility in West Africa: uncertainties and need for prospective cohort studies. Liver International 2017;37:1116-21.

22 Babor TF, Higgins-Biddle JC, Saunders JB, et al. The Alcohol Use Disorders Identification Test: Guidelines for Use in Primary Care [Internet. 41. World Health Organization (WHO), http://apps.who. int/iris/bitstream/handle/10665/67205/WHO_MSD_MSB_01.6a.pdf; jsessionid=3743A977A779D807D1894679A3E91DD3? sequence $=1$

23 Global Adult Tobacco Survey Collaborative Group. Centers for Disease Control and Prevention (CDC). Tobacco Questions for Surveys: A subset of key questions for the Global Adult Tobacco Survey (GATS) [Internet. Atlanta, Georgia: Centers for Disease Control and Prevention, 2011. http://www.who.int/tobacco/ surveillance/en_tfi_tqs.pdf

24 Kessler RC, Andrews G, Colpe LJ, et al. Short screening scales to monitor population prevalences and trends in non-specific psychological distress. Psychol Med 2002;32:959-76.

25 Amon J, Brown T, Hogle J, et al. Guidelines for repeated behavioral surveys in populations at risk of $\mathrm{HIV} ; 358$.

26 Foxcroft DR, Smith LA, Thomas $\mathrm{H}$, et al. Accuracy of alcohol use disorders identification test for detecting problem drinking in 18-35 Year-Olds in England: method comparison study. Alcohol and Alcoholism 2015;50:244-50.

27 Gache P, Michaud P, Landry U, et al. The alcohol use disorders identification test (audit) as a screening tool for excessive drinking in primary care: reliability and validity of a French version. Alcoholism: Clinical \& Experimental Research 2005;29:2001-7.

28 Andrews G, Slade T. Interpreting scores on the Kessler psychological distress scale (K10). Aust N Z J Public Health 2001;25:494-7.

29 Korhonen C, Kimani M, Wahome E, et al. Depressive symptoms and problematic alcohol and other substance use in 1476 gay, bisexual, and other MSM at three research sites in Kenya. AIDS 2018;32:1507-15.

30 Liu Y, Ruan Y, Strauss SM, et al. Alcohol misuse, risky sexual behaviors, and HIV or syphilis infections among Chinese men who have sex with men. Drug Alcohol Depend 2016;168:239-46.

31 Weiss HA, Vandepitte J, Bukenya JN, et al. High levels of persistent problem drinking in women at high risk for HIV in Kampala, Uganda: a prospective cohort study. Int J Environ Res Public Health 2016;13:153. 
32 Petoumenos K, Law MG, Smoking LMG. Smoking, alcohol and illicit drug use effects on survival in HIV-positive persons. Curr Opin HIV AIDS 2016;11:514-20.

33 Jaquet A, Ekouevi DK, Aboubakrine M, et al. Tobacco use and its determinants in HIV-infected patients on antiretroviral therapy in West African countries. Int J Tuberc Lung Dis 2009:13:1433-9.

34 Schneider M, Chersich M, Temmerman M, et al. The impact of alcohol on HIV prevention and treatment for South Africans in primary healthcare. Curationis 2014;37:1137.

35 Wray TB, Grin B, Dorfman L, et al. Systematic review of interventions to reduce problematic alcohol use in men who have sex with men. Drug Alcohol Rev 2016;35:148-57.

36 Yi S, Tuot S, Chhoun P, et al. Mental health among men who have sex with men in Cambodia: implications for integration of mental health services within HIV programmes. Int $J$ Equity Health 2016;15:53.

37 Stoloff K, Joska JA, Feast D, et al. A description of common mental disorders in men who have sex with men (MSM) referred for assessment and intervention at an MSM clinic in Cape town, South Africa. AIDS Behav 2013;17:77-81.
38 Patel SK, Saggurti N, Pachauri S, et al. Correlates of mental depression among female sex workers in southern India. Asia Pac J Public Health 2015;27:809-19.

39 Nakimuli-Mpungu E, Mutamba B, Othengo M, et al. Psychological distress and adherence to highly active anti-retroviral therapy (HAART) in Uganda: a pilot study. Afr Health Sci 2009;9 Supp 1:S2-7.

40 Ye S, Yin L, Amico R, et al. Efficacy of Peer-Led interventions to reduce unprotected anal intercourse among men who have sex with men: a meta-analysis. PLoS One 2014;9:e90788.

41 Shangani S, Escudero D, Kirwa K, et al. Effectiveness of peerled interventions to increase HIV testing among men who have sex with men: a systematic review and meta-analysis. AIDS Care 2017;29:1003-13.

42 Chuang D-M, Lacombe-Duncan A. Community engagement among men who have sex with men living with HIV/AIDS in Taiwan. AIDS Care 2016;28:445-9.

43 Joint United Nations Programme on HIV/AIDS (UNAIDS). The Western and Central Africa Catch-up plan: Putting HIV treatment on the fast-track by 2018 [Internet], 2017. Available: https://www.unaids. org/sites/default/files/media_asset/WCA-catch-up-plan_en.pdf 